Apoio Cultural 
Espaço destinado aos patrocinadores dessa edição para colocar em debate idéias relacionadas aos temas de interesse do IEA. 


\title{
Transporte metropolitano e seus usuários
}

\author{
CLÁUDIO DE SENNA FREDERICO, \\ CAETANO JANNINI NETTO \\ e ARNALDO LUÍS SANTOS PEREIRA
}

“O mais importante é não parar de questionar”.

Albert Einstein

BSERVAndo-SE o caos urbano e a mobilidade na cidade de São Paulo em
1997, tem-se:

- congestionamentos de tráfego: 80 quilômetros de extensão em dias normais, chegando a picos de 200 quilômetros quando ocorrem inundações, grandes acidentes ou outros incidentes menos corriqueiros. US\$ 6 milhões diários de prejuízos em tempo e combustível gastos nesses congestionamentos;

- precariedade do transporte coletivo: duas horas por dia gastas, em média, com viagens para o trabalho (1);

- insegurança: oito silenciosas mortes por dia em acidentes de trânsito, como se anualmente caíssem sobre a cidade 24 aviões Fokker 100 (2);

- poluição: estados de alerta, de emergência e restrições periódicas à circulação de veículos provocados pelos altos níveis de poluição atmosférica, cujos principais contribuintes são os veículos automotores, responsáveis por $90 \%$ da emissão de gases.

O panorama desalentador dos transportes urbanos na região metropolitana de São Paulo, além de despertar questionamentos quanto a ações e investimentos por parte das autoridades, suscita infindáveis discussões amplificadas pela mídia, que atua no mais das vezes como caixa de ressonância das opiniões e expectativas da classe média urbana.

Entre os temas recorrentes nessas discussões figuram com destaque, e muitas vezes em conjunto, a deficiência dos transportes coletivos e a necessidade de redução do uso do transporte individual.

A grande, se não a esmagadora, maioria das opiniões converge para a necessidade de melhor qualidade com relação ao transporte público, objetivando 
que a população motorizada deixe seus veículos em casa. A afirmativa seria correta caso não partisse de premissa no mínimo incerta, se não equivocada: de o motorista estar disposto a não utilizar seu automóvel, passando a fazer suas viagens, em particular aquelas com motivo trabalho, por transporte coletivo.

Outro tema recentemente em voga trata da existência das chamadas peruas. A denominação, antes somente dirigida às kombis empregadas como lotação, hoje abrange espectro mais amplo e diversificado de veículos e tipos de serviço.

Aparentemente os dois temas nada têm em comum. Muito menos teriam relação com a proposta que este trabalho encerra. Os três, entretanto, têm relação com uma terceira matéria, muito pouco tratada, estudada e trabalhada: o usuário e o mercado de transportes urbanos.

\section{As dimensões e os rumos do mercado}

\footnotetext{
"Se acontecer tudo isso que a gente está falando, o que é um sonho, uma utopia, se tiver mais trem com intervalo de 15 em 15 minutos e um espaço para nós, está ótimo.”

Usuária dos trens metropolitanos de São Paulo
}

Ao tratar-se da questão mercado de transporte urbano em São Paulo, trabalha-se com um universo cujas dimensões dão a melhor idéia de sua importância. Os dados apresentados a seguir foram extraídos da Pesquisa Origem-Destino 1987, atualizados para 1992:

- cerca de 16,5 milhões de habitantes, distribuídos em 39 municípios (3);

- frota de 4,9 milhões de veículos, incluídos 11 mil ônibus (4);

- cerca de 34 milhões de viagens diárias - dados 1993 (5) -, divididas conforme a seguinte tabela:

Região metropolitana de São Paulo:

distribuição de viagens segundo meio de transporte - 1977 e 1993 (6) número de viagens x 1.000

\begin{tabular}{|c|c|c|c|c|}
\hline \multirow{2}{*}{ Meio de transporte } & \multicolumn{2}{|c|}{1977} & \multicolumn{2}{|c|}{1993} \\
\hline & Viagens & $\%$ & Viagens & $\%$ \\
\hline Total de viagens & 29.400 & 100,0 & 34.338 & 100,0 \\
\hline Subtotal viagens a pé & 10.650 & 36,2 & 13.209 & 38,5 \\
\hline Subtotal motorizadas & 18.750 & 63,8 & 21,129 & 61,5 \\
\hline Por automóvel & 8.296 & 28,2 & 9.264 & 27,0 \\
\hline Por coletivos & 10.454 & 35,6 & 11.865 & 34,6 \\
\hline
\end{tabular}


O conhecimento desse universo em todas as suas facetas é um dos desafios a serem vencidos pelos planejadores, gestores e operadores do sistema de transportes da região metropolitana.

O estudo da evolução dos sistemas, das mutações no comportamento da cidade e de seus usuários parte desse conhecimento, apresenta movimentações por vezes imprevistas, que alteram os pressupostos estabelecidos para os projetos e, em decorrência, exigem alterações nos rumos desses trabalhos.

\title{
O privilégio ao transporte individual
}

\author{
"A gente pensa em melhorar de vida, \\ a primeira coisa é: sair fora do trem. \\ Nunca se pensa em melhorar o trem, \\ a gente pensa em sair do lugar." \\ Usuário dos trens metropolitanos de São Paulo
}

As populações urbanas brasileiras, em particular a de São Paulo, fizeram a opção pelo transporte individual e agora sentem os efeitos nefastos de tal escolha, discutindo e aparentemente procurando saídas que representem perdas menores do que aquelas hoje sofridas com os congestionamentos diários.

Um breve inventário dos investimentos em sistemas de transporte coletivo de média e alta capacidades na região metropolitana de São Paulo nas últimas três décadas pode servir como referencial na análise da evolução desses sistemas frente aos aumentos de demanda observados:

- em 1968 tiveram início as obras da primeira linha do metrô, a Linha Norte-Sul, inaugurada em 1974;

- no período 1977 a 1981 implantaram-se as faixas exclusivas, intervenções no âmbito da fluidez do sistema de ônibus, visando sua melhor eficiência sem que se pudesse, entretanto, classificar aqueles corredores como de média capacidade;

- em 1979, cinco anos após a inauguração da primeira linha, inaugurouse a o primeiro trecho da Linha Leste do metrô, concluída somente em 1988;

- em 1984 completaram-se os investimentos do Estado nas linhas de trens metropolitanos da Fepasa (a oeste e sul da região metropolitana), enquanto definhava o sistema de trens da Rede Ferroviária Federal (depois CBTU), em poder da União;

- em 1985 foi implantado o primeiro corredor de ônibus na cidade, o da avenida Santo Amaro, que entrou em operação sem seus pressupostos de projeto (que previa eletrificação e troncalização do sistema, levando-o a desempenho correspondente ao de sistema de média capacidade, o que nunca chegou a ocorrer); 
- em 1988 inaugurou-se o corredor metropolitano de onibus interligando $\mathrm{O} A \mathrm{ABC}$ e este à estação Jabaquara do metrô; tratava-se do primeiro corredor com características efetivas de sistema de média capacidade (via inteiramente segregada, bilhetagem eletrônica, terminais de integração, volumes hoje próximos aos 250 mil passageiros por dia);

- em 1990 entrou em operação o segundo corredor de ônibus municipal, ligando Vila Nova Cachoeirinha ao centro da cidade;

- em 1992 iniciou-se a operação do trecho Clínicas-Ana Rosa da Linha 2 do metrô, correspondente a 4,7 quilômetros de um total de 16,7.

O conjunto das intervenções apontadas representou oferta adicional da ordem de 4 milhões de passageiros por dia, enquanto o número de viagens motorizadas no período 67-93 cresceu cerca de 14 milhões de viagens por dia. A diferença, de cerca de 10 milhões de viagens adicionadas, foi absorvida pelo sistema de baixa capacidade (ônibus) e pelo transporte individual (7).

No mesmo período, aumentou a participação do transporte individual, que subiu de 31,9\% do total de viagens motorizadas em 1967 para 43,8\% em 1993, enquanto a participação das viagens por coletivos sobre o mesmo total caiu de 68,1\% em 1967 para 56,2\% em 1993 (8).

Os investimentos no transporte coletivo, embora aparentemente numerosos, demonstram descontinuidade ou lentidão dos processos de expansão (caso do metrô e das diversas modalidades de corredores de ônibus) e ou caráter espasmódico das ações do Estado (caso dos trens metropolitanos).

Durante esse período, as administrações municipais, premidas pelo crescimento vertiginoso da frota de automóveis e pelos congestionamentos, trataram de ampliar o sistema viário e os instrumentos para sua operação.

O resultado, ao longo do tempo, foi o acirramento da tendência de favorecer o transporte individual gerando, por conseqüência, o aumento do desequilíbrio nas taxas de mobilidade.

Enquanto a minoria de renda mais elevada dispôs, historicamente, de graus de mobilidade invejáveis, a maioria de pobres ficou sujeita à insuficiência e à baixa qualidade dos serviços de transporte.

A chamada opinião pública, sob a influência de seus formadores (satisfeitos com sua mobilidade), desconheceu o problema, que somente veio a ser reconhecido quando a distribuição de mobilidade foi alterada em prejuízo dos possuidores de automóvel.

No momento em que as perdas com congestionamentos e poluição se avolumaram, despontou a discussão sobre a questão. A individualidade se viu ameaçada. 


\title{
Individualidade e transporte urbano
}

\author{
"Eu conheço essa linha há mais de 25 anos \\ e acompanhei a involução. Era bonito. A gente \\ tinha vergonha de tomar esse trem com qualquer roupa" \\ Usuário dos trens metropolitanos de São Paulo
}

O culto à individualidade, fenômeno associado indelevelmente ao processo de crescimento da chamada economia de mercado ou sociedade de consumo, mais que um simples eco, encontrou campo fértil na área dos deslocamentos urbanos.

Afora a recorrente simbologia correlata à posse do automóvel, o transporte individual representou a opção menos restritiva aos deslocamentos do cidadão, tendo ainda, como atrativo extra, melhores condições de conforto. $\mathrm{O}$ transporte coletivo, em oposição, oferece restrições ao mais livre deslocamento dos cidadãos.

Em tese, não considerados os efeitos decorrentes de sua própria reprodução, o uso do automóvel apresenta como vantagens:

- liberdade horária: o dono do carro sai de sua origem no momento em que desejar, sem estar sujeito a horários pré-fixados, como é o caso do transporte coletivo;

- liberdade na escolha de trajetos possibilitando, em tese, ganhos de tempo e possiblidade de múltiplos destinos sucessivos numa mesma viagem;

- atendimento porta a porta: o usuário não está sujeito a deslocamentos intermediários entre a origem ou o destino de sua viagem e o ponto onde o transporte coletivo presta seu atendimento;

- invidualidade propriamente dita: o proprietário do automóvel pode, em tese, selecionar seus companheiros de viagem; talvez a principal opção seja não ter companheiros de viagem; ao contrário, no transporte coletivo está sujeito à convivência com parceiros compulsórios;

- maior conforto: viaja sentado, dispondo de uma série de serviços destinados a proporcionar condições ambientais mais agradáveis (ar condicionado, aparelhos de rádio e reprodução de som, automação de atividades, telefonia móvel etc.).

A indiscutível vantagem teórica do uso do automóvel vê-se, entretanto, abalada pelas dificuldades que sua disseminação acarreta. A convivência entre números elevados de veículos não é pacífica nem tranqüila. Desde os primórdios do automóvel, à necessidade de regulação do tráfego corresponderam restrições à circulação, diminuindo progressivamente a vantagem da escolha de trajetos. 
A escassez de espaços públicos para o estacionamento de veículos obrigou a restrições crescentes, prejudicando o atendimento porta a porta.

O crescimento geométrico das taxas de motorização nos centros urbanos ficou muito acima da capacidade de o setor público atender a tal demanda com sistemas viários adequados. Os decorrentes congestionamentos passam a diminuir e, por vezes, a anular a liberdade horária. Nas horas de pico, o uso do automóvel passa a ser regido pelo horário em que o congestionamento seja menor.

Restam como vantagens indissociáveis o conforto e a individualidade. A resposta da indústria é a oferta de produtos dotados de maiores e mais sofisticados itens de conforto. A individualidade é atributo mais e mais decantado na propaganda de automóveis.

Em cidades com níveis exasperantes de congestionamento, como ocorre em Bangcoc, as facilidades eletrônicas, como computadores portáteis e telefonia móvel, fazem com que os automóveis passem a servir como escritórios itinerantes: seus usuários trabalham enquanto perdem horas em seus deslocamentos.

As restrições e inconvenientes decorrentes da convivência entre os automóveis no cenário urbano podem, em casos extremos, significar a anulação das vantagens intrínsecas daquele transporte. Assim, o transporte coletivo pode aproximar-se do transporte individual na preferência do usuário.

Ocorre, entretanto, que tal transferência não se dá facilmente, de forma natural, resultado do simples cotejo de eficiência entre sistemas. Abandonar o uso do transporte coletivo, aderindo ao uso do automóvel é um processo quase natural, de resto associado à ascensão social. $\mathrm{O}$ contrário, abandonar o uso do transporte individual em benefício do coletivo pode simbolizar retrocesso social, não realizado sem alguma troca, que pode representar, no mais das vezes, qualidade diferenciada nesse coletivo.

Parece ser esse o caso do momento vivenciado na região metropolitana de São Paulo. Observa-se, na comunidade e na mídia, palavras de condenação ao uso do automóvel. Sem efetiva e científica aferição, tais movimentos podem deixar a impressão que a classe média urbana estaria disposta a trocar o conforto do automóvel pelo uso do coletivo, em particular do metrô. A opinião, amplamente divulgada, pode entretanto diferir da disposição efetiva do comportamento desse segmento social. A simples divulgação de opiniões pontuais poderá estar disfarçando um comportamento não revelado: o de que "o transporte coletivo é muito bom para o vizinho de congestionamento que, se passar a usar metrô, vai deixar a via mais livre para que eu possa usar men automóvel de maneira mais confortável".

De qualquer maneira, transparece a idéia de que qualquer movimentação na divisão modal a favor do transporte coletivo passa por uma transformação desse modo, aproximando-o dos requisitos de conforto oferecidos pelo automóvel. 


\title{
O transporte coletivo urbano e seu mercado
}

\author{
"Quando tínhamos todas as respostas, \\ mudaram as perguntas." \\ Pichação anônima
}

A busca da chamada economia de mercado vem provocando uma torrente de opiniões, lançando na conta do mercado todas as possíveis soluções para os mais diversos problemas. Os resultados parecem mostrar que a fórmula vem conseguindo sucesso: produção, produtos, vendas e distribuição em escalas vertiginosamente altas; sucessivas pesquisas de mercado, com graus crescentes de sofisticação e acerto; profissionais de mercado buscando incessantemente produtos que atendam à satisfação de milhões e milhões de consumidores.

Paradoxalmente ou não, o trabalho de conquista de multidões de consumidores passa pela sedução da individualidade: cada vez mais se vende a personalização do produto ou serviço, a sensação de conquista pessoal, a autosatisfação.

Em linha paralela, desenvolvem-se os princípios da qualidade total, que levam para dentro das organizações, entre outros, um conceito fundamental: o principal objetivo de uma organização comercial deve ser atender bem a seus clientes.

Na história dos transportes públicos no Brasil e, em particular, na região metropolitana de São Paulo verifica-se terem sido poucas as iniciativas que trataram o usuário daquele serviço como um consumidor. Assim, o transporte coletivo recebeu pouco tratamento mercadológico ao longo de sua existência, entendendo-se como tal o tratamento do produto transporte e das relações dos operadores (produtor) com a comunidade usuária (cliente).

No extremo oposto, e não por coincidência, o transporte individual tem sido, desde a implantação da indústria automobilística no país, um dos produtos mais trabalhados e difundidos sob o ponto de vista mercadológico, valorizando principalmente a propriedade do carro como indicador de status social.

Diversos fatores podem explicar a ausência do tratamento mercadológico na implantação e operação dos sistemas de transporte coletivo.

De início, o marco divisório entre possuir ou não possuir automóvel. Durante décadas o transporte coletivo vem sendo considerado como o meio de locomoção para as populações de baixa renda. E assim foi tratado. As propaladas deseconomias do sistema foram sempre amplamente compensadas pela baixa qualidade na prestação do serviço.

A baixa capacidade de organização ou de reivindicação da população usuária contribui para um provável desleixo dos operadores com os níveis de serviço oferecidos. Essa baixa capacidade de organização resulta em aparente passivida- 
de, rompida quando dos caóticos movimentos de depredação e incêndio de terminais e equipamentos, cujo potencial de pressão sobre os agentes operadores acaba sendo pontual e, portanto, limitado.

A presença crônica de demandas reprimidas pode colaborar para a falta de esforços dos gestores e operadores no sentido de melhor conhecer e atender seu mercado. Sua existência induz ao raciocínio de que o nível de serviço não guarda qualquer relação com o número de usuários pagantes.

O transporte coletivo foi sempre tratado como dever do Estado. Tal premissa pode muitas vezes ser associada à decantada ineficiência do setor público como operador, em qualquer área, gerando certa descrença da população quanto ao nível de serviços poder ser melhorado, traduzida em sua passividade.

No transporte por ônibus a presença do Estado, alternada ou simultaneamente como operador ou como gestor, escondeu sempre a presença de mercado atrativo e de ampla rede de operadores privados bem-sucedidos em seus negócios. A qualidade dos serviços oferecidos à população oscilou proporcionalmente à quantidade de subsídios pagos pelo governo.

No transporte sobre trilhos, sob gestão estatal desde a década de 60, o trem metropolitano decorreu da urbanização do trem de passageiros de longo curso. Mal visto pelos gestores das ferrovias, uma vez que atrapalhava o transporte de cargas, mais rentável, foi submetido a décadas de abandono. Hoje, busca e caminha para afirmar-se como um sistema efetivo de transporte urbano, com tecnologia e procedimentos próprios, assemelhado mas não igual ao transporte metroviário.

Operando a partir de 1974, o Metrô de São Paulo constitui um exemplo à parte na história dos transportes coletivos. Oferecendo serviços com padrões superiores aos demais sistemas, transformou-se em símbolo de bom serviço, reconhecido como tal mesmo pela população não-usuária.

Na história da implantação do sistema podem ser identificadas causas de seu sucesso. Foi implantado como um sistema novo e não como sucessor ou adaptação de sistemas então existentes - caso dos ônibus que sucederam os bondes, com veículos adaptados a partir dos chassis de caminhões; e do trem metropolitano, herdeiro do trem de passageiros de longo curso. A par de inúmeras capacitações, os responsáveis por sua implantação trataram, oportunamente, de não buscar, em termos de procedimentos operacionais e relações com usuários, referências nos sistemas então em funcionamento: procuraram criar suas próprias diretrizes e procedimentos.

Para tal intento, uma iniciativa até então inédita: procurou-se, durante o período de implantação, conhecer melhor seus potenciais futuros usuários, suas expectativas, seus valores. Formou-se uma equipe especialmente destinada a estudar as relações com essa população, coordenada e constituída por profissionais oriundos da área de marketing. Além de inúmeros trabalhos com objetivos mais 
específicos, em 1974 realizou-se a Pesquisa de Atitudes do Usuário de Transportes, efetuada em conjunto pela equipe da Cia. do Metrô e pelo Departamento de Psicologia Social da PUC-SP. Fruto desse conjunto de ações, o Metrô-SP iniciou suas operações dando ao usuário um nível de serviços que ele desconhecia, embora esperasse. O sucesso como sistema de transporte foi conseqüência natural.

Interessante observar as preocupações atuais dos sistemas europeus de transporte coletivo. Os principais centros da Europa, historicamente dotados de extensos sistemas de alta capacidade, nunca manifestaram preocupações específicas quanto à satisfação de seus usuários. Limitaram-se a expandir suas redes, garantindo níveis de oferta elevados, com níveis de serviço razoáveis.

Nos últimos 10 a 15 anos, essas metrópoles passaram a conviver mais intensamente com o fenômeno dos congestionamentos. Paralelamente, os operadores de transporte coletivo passaram a preocupar-se mais intensamente com seus usuários. Tal preocupação é demonstrada pelos temas apresentados para o $52^{\circ}$ Congresso da União Internacional dos Transportes Públicos (UITP), a realizar-se no próximo mês de junho em Sttutgart, na Alemanha. Ao contrário dos congressos anteriores, em que os temas tratavam predominantemente dos aspectos tecnológicos ligados à expansão e operação, neste os temas tratam mais numerosa e intensamente das questões ligadas às relações entre o operador e seu usuário.

O caso de Paris é exemplar e esclarecedor. Dotada de cerca de 400 quilômetros de rede de metrô e trens metropolitanos, a cidade hoje convive com níveis de congestionamento insuportáveis para seus cidadãos.

A RATP (Régie Autonome des Transports Parisiens), autoridade dos transportes públicos metropolitanos de Paris, vem trabalhando em três frentes de aproximação ao usuário, de modo a atraí-lo para o transporte público, sugerindo uma política de contraposição ao crescimento do uso do carro:

- a expansão do sistema metroviário, em particular no caso do sistema Météor, se faz sob inovações tecnológicas que, além de prover os tradicionais requisitos de maior eficiência técnica, oferecem aos usuários inovações significativas relativas ao conforto;

- a implantação de uma política de gestão por linha, pela qual cada uma das redes disporá de graus elevados de autonomia, com resultados aferidos a partir de contratos de gestão. Processo semelhante também vem sendo implantado no metrô de Londres. Tal autonomia objetiva o melhor desempenho econômico do sistema, mas é extensiva à relação da equipe de gerência da linha com sua clientela;

- a implantação de efetiva política de relações com os usuários, traduzida no trato diário com seus clientes, no estudo de seus comportamentos e expectativas, na adoção de partidos de projeto e operação que atendam a essas expectativas. 
Curiosamente, parte dos temas a serem apresentados no Congresso da UITP, assim como parte dos trabalhos de aproximação da RATP com seus usuários, foram objetos de estudos semelhantes quando da implantação do metrô de São Paulo há 23 anos.

O grau de qualidade dos serviços no Metrô-SP foi mantido ao longo de sua história com pequenas variações. Não obstante essa experiência ter sido tão bem-sucedida, ela não se disseminou para os demais modos.

Analisando-se o desenvolvimento do estudo dos transportes públicos no Brasil, constata-se rápida evolução no campo das demandas, ligado visceralmente ao planejamento de transportes. No caso de São Paulo, esse desenvolvimento é notável. No corrente ano de 1997, deverá realizar-se a quarta Pesquisa OrigemDestino, em continuação e atualização àquelas efetuadas nos anos de 1967, 1977 e 1987. Amplo repositório de informações sobre os deslocamentos da população, encerra ainda informações socioeconômicas sobre essa população, de maneira a embasar as projeções das demandas para o futuro. Sofisticados modelos matemáticos são alimentados por essas informações, gerando prognósticos com alta credibilidade.

O mesmo desenvolvimento, entretanto, não logrou o estudo do comportamento e das atitudes dessa população. Não se tem conhecimento de outra pesquisa sobre as atitudes do usuário de transportes em continuação ao citado estudo da década de 70. Tampouco foram transferidos e adaptados para os transportes urbanos os avanços observados na Psicologia Social aplicada ao marketing.

A única iniciativa conhecida nessa direção foi a da Associação Nacional dos Transportes Públicos (ANTP) que, juntamente com o Instituto Gallup, efetua pesquisa semestral de opinião dos usuários e da população com relação aos sistemas de transportes da cidade. Entretanto, trata-se de levantamento restrito à opinião dos usuários e da população, não tratando das atitudes, comportamentos e expectativas desses grupos nas suas relações cotidianas com o sistema.

\section{$\mathrm{O}$ fenômeno das peruas}

\footnotetext{
"Não interessa quanto você gosta de vegetais. Nunca tente alimentar um gato com cenouras."
}

Alex McEachern

O recente e atual recrudescimento da demanda e oferta de serviços de transporte por peruas na região metropolitana de São Paulo oferece ao planejador e operador de transportes uma oportunidade de reflexão, servindo como alerta de que o tratamento dispensado ao usuário do sistema merece, no mínimo, uma revisão.

O tipo de serviço (um modal?) não é novo. Pelo menos até meados de 1960, a cidade contava com as lotações, que supriam a demanda de um transporte 
de melhor qualidade, situado entre o táxi e os ônibus. Nada mais eram que táxis oferecendo, nas horas de pico, serviço coletivo (lotação completa do veículo, daí a denominação). Alguns veículos, com dimensões ligeiramente maiores, apresentavam um segundo banco traseiro escamoteável, aumentando o número de passageiros atendidos.

O serviço era de alguma forma regulamentado, apresentando características regulares:

- pontos iniciais e finais determinados e sinalizados;

- tarifa uniforme (regulamentada);

- trajeto fixo, permitidas pequenas variações em casos de congestionamentos ou situações extraordinárias;

- inexistência de pontos de parada intermediários pré-estabelecidos.

Extinto no decorrer da década de 60, o serviço de lotação reapareceu nos anos 70 , já utilizando peruas kombi e atuando de forma clandestina, reprimido intermitentemente pelas autoridades de trânsito e transportes na ocasião.

O crescimento desse tipo de transporte nos últimos anos, a sua diversificação em termos de tipos de veículos e de serviços, a repressão das autoridades e a razoável visibilidade na imprensa despertaram o debate. Tal repercussão evidencia, antes de outras considerações, o sucesso do produto.

Antes de debater-se a necessidade ou não de sua institucionalização e regulamentação, seria interessante reconhecer as origens do crescimento desse tipo de transporte, suas características e as vantagens oferecidas que o levaram ao sucesso.

Num raciocínio análogo ao procedido anteriormente para o transporte individual frente ao transporte coletivo, examinem-se, de início, as características dessa modalidade que a diferenciam do transporte coletivo comum:

- melhor padrão de conforto para os passageiros, por permitir que viajem sentados;

- maior flexibilidade no percurso dos veículos, que podem contornar áreas de trânsito intenso ou vias congestionadas, resultando em menores tempos de viagem;

- maior flexibilidade de trajetos e pontos de parada, propiciando transporte virtualmente domiciliar a clientes cativos;

- maior sensação de segurança em decorrência da virtual individualização do transporte, visto que o hábito regular propicia maior aproximação entre o motorista e seus clientes cativos e maior socialização entre os usuários cativos; 
- otimização das rotas dos veículos em termos de pontos de origem e destino, percurso e freqüência, propiciando resultados econômicos favoráveis aos seus operadores/proprietários;

- a partir do advento das peruas importadas, com melhores condições de conforto, ampliação do espectro de tipos de serviço, abrangendo transporte diferenciado entre bairros e estações do metrô, ocupando, nesse caso, o espaço do automóvel.

Parte dessas vantagens estão associadas à maior individualidade proporcionada pelas peruas com relação ao transporte coletivo convencional, sugerindo nova modalidade de demanda, até então não observada: a de um modo de transporte intermediário entre o coletivo e o individual.

Parcela das vantagens apontadas decorre, paradoxalmente, do alto grau de informalidade e nenhuma regulamentação observados no sistema. Como desvantagens principais, estão aquelas permanentemente associadas ao combate à desregulamentação:

- oferta de serviços somente nas linhas, horários e pontos rentáveis;

- falta de condições de segurança nos veículos;

- oscilações de tarifa em função de mercado.

Neste texto não se pretende a discussão da questão em seus aspectos conceituais de regulamentação, mas chamar a atenção para o fato de tal tipo de serviço ser uma novidade criada a partir de demandas do mercado, demandas essas desconhecidas dos planejadores, gestores e operadores de transportes coletivos na cidade por falta de conhecimento, desatenção ou erro de avaliação.

Algumas perguntas ainda não respondidas, ou respondidas sem bases científicas, sugerem algum desconhecimento do fenômeno por parte das autoridades e agentes do setor:

- quais são os números desse sistema: veículos, passageiros transportados etc.?

- qual a fisiologia do sistema: rotas atendidas, tipos de transporte, tipos de localização nos pontos iniciais e finais?

- qual o perfil dos operadores: desempregados, taxistas, novos pequenos empresários, cooperativas?

- qual o perfil dos usuários por tipo de serviço: renda, profissão, sexo, motivos de viagem etc.?

- quais os motivos que levaram esse usuário a adotar o sistema: rapidez, conforto, segurança etc.? 
- o sucesso do sistema decorre de alterações no perfil de renda dos usuários ou simplesmente da baixa oferta ou poucas opções de transporte?

Os operadores privados de transporte coletivo (ônibus) aparentemente também foram surpreendidos pelo fenômeno, uma vez que não há indícios de sua assimilação, isto é, não há indícios de operadores de ônibus atuando no sistema de peruas. A reação dos diversos agentes do sistema, traduzida inicialmente em repressão, seguida do estudo de alternativas de institucionalização, parece disfarçar certa perplexidade. O estudo sistemático e científico do comportamento, expectativas e atitudes do usuário de transportes urbanos talvez pudesse diminuir tal perplexidade e antecipar ações no sentido de atender melhor às demandas.

\title{
Usuário e fiscalização dos serviços
}

\author{
"Se um marginal, uma pessoa que está acostumada \\ num lugar qualquer e chega num lugar que está jogado \\ às traças ele se sente à vontade, ele está no habitat natural dele. \\ Ali ele pode agir. Mas se ele chega num lugar um pouco melhor, \\ se ele vê que tem certas regras a serem seguidas ele vai pensar: aí não \\ é meu meio. Ele vai se sentir inibido...” \\ Usuário dos trens metropolitanos de São Paulo
}

O ressurgimento das concessões como alternativa para provimento de maior oferta de infra-estrutura e serviços, de melhores níveis de serviço ou mesmo de diminuição de subsídios desembolsados pelo Estado provoca, do lado do agente público, nova preocupação: os organismos, métodos e procedimentos de fiscalização dos prestadores privados dos serviços.

No campo dos transportes coletivos urbanos tal preocupação é maior, tendo em vista o histórico dos serviços privados, a existência de demandas reprimidas, a capacidade de pagamento da população e as dificuldades na fiscalização cotidiana.

A gestão dos serviços de transporte coletivo, em particular sua fiscalização, evoluiu consideravelmente nas últimas décadas no campo técnico: índices de desempenho, cadastramento e licenciamento dos veículos, padrões de aferição do estado dos veículos, registros de freqüência, índices econômicos setoriais etc. fazem parte de um rol de procedimentos e normatizações que foram desenvolvidos, buscando assegurar a qualidade dos serviços e a sua correta remuneração.

Os progressos no campo da eletrônica e da telecomunicação potencializam essa fiscalização técnica a limites antes inimagináveis, como a possibilidade de controle de cada veículo em tempo real através de rastreamento por satélite, identificação passo a passo das viagens feitas em cada veículo por meio da bilhetagem eletrônica etc. O usuário, entretanto, pouco participa como agente da fiscalização. Identificam-se apenas duas vertentes em coleta de informações 
diretamente do usuário: a pesquisa de opinião da ANTP, citada anteriormente, e os serviços de atendimento a reclamações. A pesquisa de opinião ANTP-Gallup teve importante caráter inovador, servindo de referência de desempenho dos diversos sistemas na região metropolitana de São Paulo.

A medida do sucesso do estudo reflete-se na expectativa dos operadores, vivida semestralmente quando da divulgação dos resultados. Entretanto, seus objetivos plenamente alcançados não cobrem mais detalhadamente cada linha, empresa ou serviço, tampouco seus resultados podem ser empregados como parâmetros de fiscalização.

Os serviços de atendimento a reclamações, de resto existentes há muito tempo, pouco foram utilizados como aferidores de desempenho. O exemplo mais conhecido, e que levou mais a fundo a reclamação como indicador de desempenho, é o adotado em Vitória, Espírito Santo, no Sistema Intermunicipal de Transporte Coletivo Urbano por Ônibus da Grande Vitória. Nesse sistema, o número de reclamações é incluído, junto a uma série de outros parâmetros, na sistemática de Avaliação de Desempenho das Operadoras, para a obtenção de índices de desempenho das empresas operadoras privadas, que servirão para sua fiscalização, remuneração e penalização (9).

A limitação de tal metodologia é a existência da reclamação pressupor a disposição e a iniciativa do usuário, excluindo-se aquele mais passivo que não tem disposição nem iniciativa de se dirigir ao gestor público para formalizar a reclamação, por maiores sejam as facilidades oferecidas para tanto.

Uma terceira vertente, menos presente no transporte coletivo, trata da representação da sociedade civil nas atividades de planejamento e gestão de serviços públicos. Atendendo ao chamado planejamento participativo, a alternativa vem sendo crescentemente empregada a partir do fim do regime militar, contemplada em inúmeros diplomas legais voltados ao planejamento e/ou fiscalização de serviços públicos. A dúvida lançada sobre tal modalidade de participação refere-se aos representantes da sociedade civil e à forma como eles são apontados.

$\mathrm{Na}$ maior parte dos casos, a representação veio a ser assumida por entidades de classe, organizações não-governamentais de diferentes naturezas, sem ficar efetivamente comprovado o grau de representatividade de que tais entidades dispõem com relação ao universo de contribuintes ou usuários.

\section{A proposta}

"O começo é a parte mais importante do trabalho."

Platão

O que se propõe é a utilização de métodos científicos de pesquisa junto aos usuários do transporte coletivo da região metropolitana de São Paulo, de maneira que seus resultados possam servir como índices de desempenho dos 
operadores privados e, por conseqüência, adotados como parâmetros de penalização ou premiação a esses operadores.

Inicialmente propugna-se o desenvolvimento de uma metodologia que contemple:

- os aspectos técnicos envolvendo, entre outros, universo, amostragem, tipo de entrevista, objetos, método de coleta, periodicidade, tabulação e sumarização;

- aspectos institucionais que envolvem os organismos fiscalizadores, em particular a formação de comissões arbitrais como instância administrativa de recurso;

- aspectos jurídicos e administrativos envolvendo o embasamento legal dos instrumentos e medidas, assim como a formulação dos instrumentos de aplicação das pesquisas, penalidades e prêmios.

Estabelecido o modelo, proceder-se-ia ao cadastramento de entidades de pesquisa, que, submetidas a um processo de qualificação e seleção, seriam homologadas como agentes aptos à execução dos trabalhos, concorrendo a processos convencionais de licitação e contratação. Nesse aspecto, a rotatividade, isto é, o impedimento de que uma mesma empresa pesquise sucessivamente uma mesma linha ou região, poderá conferir mais segurança aos resultados.

A proposta, no entanto, é mais abrangente. Além do estabelecimento de pesquisas de opinião como parâmetros de fiscalização, propõe-se a incorporação de pesquisas de atitudes e comportamentos junto ao usuário de transportes urbanos como instrumento de planejamento e projeto.

De uma parte, a superação do problema da congestão do sistema de transportes em São Paulo passa necessariamente pela diminuição do fosso criado entre os níveis de conforto oferecidos pelo automóvel e pelo transporte coletivo.

A redução do uso do automóvel somente será possível através de dois tipos de medidas, que podem ser aplicadas simultaneamente ou não:

- medidas de caráter repressivo: pedágio urbano, operações rodízio etc.;

- medidas de caráter persuasivo: convencimento do usuário do automóvel de que haverá vantagens na renúncia a seu uso em favor do transporte coletivo.

Os níveis de congestionamento hoje constatados favorecem uma opção do usuário pela segunda alternativa. No entanto, como trata-se de uma renúncia, alguma compensação deve contrabalançar a perda dos níveis de conforto oferecidos pelo automóvel. Tal compensação poderá resultar de serviços diferenciados, que propiciem maior individualidade e conforto no transporte coletivo. A opção pela renúncia do uso do automóvel é decisão do mercado consumidor. 
O conhecimento de tal condicionante será possível a partir de investigações desse mercado.

No lado oposto, uma massa de usuários, aparentemente com menor poder de compra, submetidos diariamente a sistemas precários, opta por um tipo de serviço não-convencional, por motivos não-suficientemente conhecidos. Tratase de questionar os serviços oferecidos institucionalmente, investigando os mecanismos que levam a essa opção, culminando por incorporar aos processos de planejamento, projeto e operação dos transportes, produtos mais compatíveis com as necessidades desses clientes.

Notas

1 Plano Metropolitano de Transporte Integrado - Relatório Síntese. São Paulo, Secretaria de Estado dos Transportes Metropolitanos, ago. 1994.

$2 I d . I b$.

3 Sumário de Dados da Grande São Paulo - 1994. São Paulo, Empresa Metropolitana de Planejamento da Grande São Paulo S.A. - Emplasa.

$4 \mathrm{Id} . \mathrm{Ib}$.

5 São Paulo - 1993 - Perfil das viagens diárias da população da metrópole. Companhia do Metropolitano de São Paulo - Metrô.

6 Sumário de Dados da Grande São Paulo, cit.

7 Id.; Pesquisa O-D/87 - Sintese das Informações. São Paulo, Companhia do Metropolitano de São Paulo - Metrô, dez. 1989.

$8 \mathrm{Id} . \mathrm{Ib}$.

9 Avaliação Mensal de Desempenho das Operadoras do Sistema Intermunicipal de Transporte Coletivo Urbano por Ônibus da Grande Vitória. Governo do Estado do Espírito Santo - Secretaria de Estado dos Transportes e Obras Públicas, mar. 1996.

Cláudio de Senna Frederico é secretário de Estado dos Transportes Metropolitanos de São Paulo.

Caetano Jannini Netto é diretor de Planejamento e Transportes Metropolitanos do Metrô de São Paulo.

Arnaldo Luis Santos Pereira é coordenador de Planejamento e Gestão dos Transportes Metropolitanos de São Paulo. 